\title{
Structure and Destruction of a Precursor: Mass-Spectrometric Evaluation of Creation of Functional Films with Predeterminated Composition
}

\author{
A. Grafov, I.A. Grafova, E. Mazurenko, L.I. Koval, S. Catinella*, P. Traldi*, G.A. Battiston** and \\ P. Zanella** \\ V.I. Vernadskii Institute of General and Inorganic Chemistry, National Academy of Sciences of Ukraine, \\ Prosp. Palladina 32/34, Kiev-142, UA-252142, Ukraine \\ * Padua Research Area Mass-Spectrometry Service, National Research Council of Italy, C.so Stati Uniti 4, \\ Area della Ricerca, 35020 Padua, Italy \\ ** Institute of Chemistry, Inorganic Technologies and Advanced Materials, National Research Council of \\ Italy, C.se Stati Uniti 4, Area della Ricerca, 35020 Padua, Italy
}

\begin{abstract}
Among a variety of applications of organometallic compounds, their use as MOCVD precursors is one of the most extensive areas. To our minds, one of the most powerful and accurate methods for evaluation and prediction of thermal behaviour of the precursor is mass-spectrometry coupled with mass-analyzed ion kinetic energy spectrometry. Traditionally, both structure and composition of deposited materials and the precursor's thermal decomposition channels were controlled by gas-phase composition, the process temperature and pressure, i.e. by extemal factors. A possibility of such a control via inner factors - i.e. structure of a specially designed precursors is demonstrated for a series of new mixed-ligand organometallic compounds of $\mathrm{In}$, $\mathrm{Zr}$ and $\mathrm{Hf}$.
\end{abstract}

\section{INTRODUCTION}

Recently the method of Metal-Organic Chemical Vapour Deposition (MOCVD) gains more and more areas of industrial application for obtaining of functional coatings and materials. This technique allows to create advanced high-effective and low-pollutant technologies which could be realized in automatized installations able to deposit a coating on pieces with a complex shape, to obtain such pieces with high precision [1]. To achieve this goal a considerable database on kinetics and mechanism of organometallic compounds thermal dissociation is needed. A complete quantitative calculations of specific thermal destruction pathways is hard or rather impossible to realize for each organometallic compound while the method of mass-spectrometry appears to be the most informative in this case and is widely used CVD chemists. One can reproduce to a maximum extent an image of thermal dissociation, to obtain an information about a stability of a molecule by comparison of mass-spectrometric analysis data [2]. In the present paper we are going to discuss massspectra obtained by EI (electron impact) at an excitation energy of $70 \mathrm{ev}$ together with mass-analyzed ion kinetic energy (MIKE) spectra extremely suitable for elucidation of fragmentation features for each particular ion.

Organometallic compounds being used as MOCVD precursors have to possess a set of specific physico-chemical data viz. high volatility at relativety low temperatures coupled with thermal stability in the vapour phase, relatively low thermal decomposition temperature, they also have to be readity available and non-toxic [2]. The above calls forth heightened fundamental and practical interest to studies dwelling on the mentioned kind of compounds as well as to a synthesis of new advanced organometallic precursors.

E.g. , indium containing materials obtained by CVD have found a variety of applications: semiconducting binary epitaxial structures (InSb), semiconducting materials containing 3 elements of the type $\mathrm{Ga}_{1 . \times} \mathrm{In}_{\mathrm{x}} \mathrm{As}$ which are used in optoelectronic and photoelectric devices [3], transparent conducting indium oxide films [4,5]. Here we discuss a gas-phase behaviour of a series of new organoindium precursors - cyclic amides of dialkylindium.

In a case of heavy transition metals, interesting as a basis of thermal barrier protective coatings, the metal tetraalcoholates with sterically demanding organic moieties seeming attractive at the first sight (by an analogy with tetrakis- $\beta$-diketonates) are hardly suitable for application in MOCVD processes. Such a conclusion could be drawn from the mass spectrum of e.g. hafnium( $N$ ) tetrakis-1,3,3-trimethyl-2- 
norbornanolate 1 its fragmentation pattern contains both alcoxo- ligand elimination and all possible variants of hydrocarbon framework cleavage. Thus, all our attention was concentrated on dicyclopentadienyl derivatives of $\mathrm{Zr}$ and Hff with bulky shielding ligands.

\section{RESLLTS AND DISCLSSION}

\subsection{Structure and fragmentation of organoindium cyclic iminoderivatives}

Indium co-ordination compounds discussed hereby are of general formula $\mathrm{R}_{2}$ InL where $\mathrm{L}=\mathrm{Me}$ or Et. L - organic imine (see table 1).

The mass-spectrometric data show that molecules of the complexes in question are dimers unstable in the vapour phase where they undergo monomerization. with an exception of methylaziridine derivatives. having therefore. the simplest fragmentation patterns consisting of consecutive cleavages first of $\ln -\mathrm{N}$ bond with a loss of the organic imino-radical followed by In-C bonds and formation of a free metal ion . For Me-4 compound exists also one more fragmentation pathway with smaller probability due to $\left[\left(\mathrm{CH}_{3}\right)_{2}[\mathrm{nN}]^{+}\right.$ $(\mathrm{m} z+159)$ ion that in tum by consecutive eliminations of methyl and nitrogen leads to the same result - free metal ion.

For all the other organoindium compounds in question the fragmentation patterns could be generalized as shown at the scheme (see fig. 1).

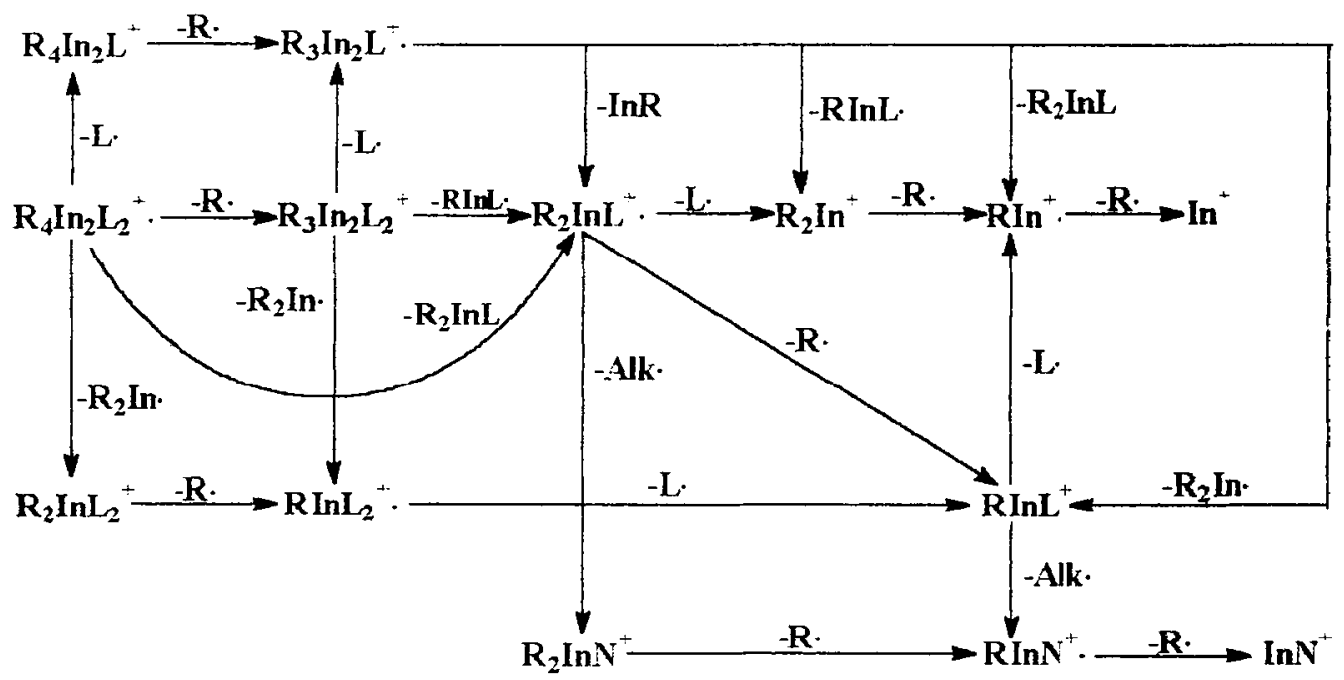

Fig.1. Generalized fragmentation pattern of $R_{\imath}$ InL complexes where $\mathrm{R}=\mathrm{Me}$ : $\mathrm{Et} . \mathrm{L}=\mathrm{NAlk}$

The dimeric molecular ion has four decomposition pathways. Tree of them are realized by imino-ligand, alkylic radical (methyl or ethyl) or dialkylindium elimination. The former two channels finally lead to a formation of monomeric $R_{2} I n L$ species which are also formed directly by monomerization. For the monomers one can find tree decomposition pathways arising from the losses of either cyclic imino-radical or alkylic one or an organic moiety bonded to the nitrogen. All these channels are connected very closely with each other and finally are leading to the free metal ion. Previously [6], for several $\mathrm{R}=\mathrm{Me}$ indium complexes under investigation only two fragmentations of the molecular ion have been found: methyl and nitrogen-containing ligand eliminations. Possibility and reliability of the other fragmentations reported at the scheme have been proved by MIKE spectra.

The table 1 reflects common and different features in a mass-spectrometric behaviour of the compounds in question. As it is evident from the EI-spectra all molecular ions of methyl-containing complexes are present as pronounced peaks (the only exception is $\mathrm{Me}-4$ one). The fragmentation of this series of compounds is occurring according to the scheme (see fig.1). but in each individual case different pathways of the molecular ion destruction become virtually prevalent. For the compound Me-1 it is the 
monomerization, for Me-2 - dimethylindium elimination, for Me-3 - the loss of methyl as the MIIKEspectra show. The processes mentioned give rise to the main products listed in the table 1 .

Table 1. Molecular and the most intensive ions in El mass spectra of organoindium cyclic iminoderivatives (italicized data correspond to monomeric species)

\begin{tabular}{|c|c|c|c|c|c|c|c|c|c|}
\hline & \multirow{3}{*}{$\begin{array}{c}\text { Structure of } \\
\text { the imino-ligand } \\
\text { L. }\end{array}$} & \multicolumn{4}{|c|}{$\mathbf{R}=\mathbf{M e}$} & \multicolumn{4}{|c|}{$\mathbf{R}=\mathbf{E} t$} \\
\hline & & \multicolumn{2}{|c|}{ molecular ion } & \multicolumn{2}{|c|}{ main ion } & \multicolumn{2}{|c|}{ molecular ion } & \multicolumn{2}{|c|}{ main ion } \\
\hline & & $1, \%$ & $\mathbf{m} / \mathbf{z}$ & [ion] $^{+}$ & $\mathrm{m} / \mathrm{z}$ & $I, \%$ & $\mathbf{m} / \mathbf{z}$ & [ion] & $\mathbf{m} / \mathbf{z}$ \\
\hline 1 & $-\mathrm{N} \simeq\left(\mathrm{CH}_{2}\right)_{4}$ & $\begin{array}{c}7 \\
100\end{array}$ & $\begin{array}{l}430 \\
215\end{array}$ & $\mathrm{Me}_{2} \mathrm{InL}$ & 215 & $\begin{array}{c}0 \\
18\end{array}$ & $\begin{array}{r}486 \\
243\end{array}$ & $\mathrm{Et}_{2} \mathrm{In}$ & 173 \\
\hline 2 & $-\mathrm{N}<\left(\mathrm{CH}_{2}\right)_{3}$ & $\begin{array}{l}15 \\
89\end{array}$ & $\begin{array}{l}+58 \\
229\end{array}$ & $\mathrm{Me}_{2} \operatorname{InL}$ & 313 & $\begin{array}{c}0 \\
-6\end{array}$ & $\begin{array}{l}514 \\
257\end{array}$ & $\mathrm{Et}_{2} \mathrm{In}$ & 173 \\
\hline 3 & $-\mathrm{N}=\left(\mathrm{CH}_{2}\right)_{3}$ & $\begin{array}{l}13 \\
9^{-}\end{array}$ & $\begin{array}{r}402 \\
201 \\
\end{array}$ & $\mathrm{Me}_{3} \mathrm{In}_{2} \mathrm{~L}_{2}$ & 387 & $\begin{array}{r}1 \\
23 \\
\end{array}$ & $\begin{array}{r}+58 \\
239 \\
\end{array}$ & $E_{2} \ln$ & 173 \\
\hline 4 & $-\mathrm{N}=\left(\mathrm{CH}_{2}\right)_{2}-\mathrm{CH}_{3}$ & $\because 1$ & 201 & $\mathrm{Me}_{2} \mathrm{In}$ & 145 & $\therefore 1$ & 239 & $\mathrm{Et}_{2} \mathrm{In}$ & 173 \\
\hline 5 & $-\mathrm{N}(\mathrm{cyclo}-\mathrm{Pr})_{2}$ & - & - & - & - & 1 & $\begin{array}{r}538 \\
269 \\
\end{array}$ & $\mathrm{Et}_{3} \mathrm{In}_{2} \mathrm{I}_{2}$ & 427 \\
\hline
\end{tabular}

Contrary to the methyl analogues, a lack or very low peak intensities of dimeric molecular species. in presence of their decomposition products are characteristic features of the El-spectra for ethyl-containing complexes. Thus in four cases the main peak appears to be $\mathrm{Et}_{2} \ln (\mathrm{m} z=173)$. The fragmentation pattem of the last compound Et-5 is the most complicated one: by loss of two cyclopropyl radicals the molecular ion forms a metastable product that gives rise to the main ion $\left[\left(\mathrm{C}_{2} \mathrm{H}_{5}\right)_{2} \mathrm{In}_{2}\left(\mathrm{NCHCH}_{2} \mathrm{CH}_{2}\right)_{2}\right](\mathrm{m} z=247)$ and ethyl radical. Further decomposition of this compound could be described in terms of the scheme 1. nevertheless some derivatives of more complex processes are also observed. e.g. simultaneous losses of ethyl and $\mathrm{NCHCH}_{2} \mathrm{CH}_{2}$, cleavage of cuclopropyl and elimination of ethy lidene etc.

\subsection{Analysis of mass spectrometric behaviour of zirconocene and hafnocene dialcoholates}

Fragmentation patterns of all organozirconium and organohafnium dialcoholates under investigation could be presented as shown in a scheme (see fig. 2).

We have for the first time synthesized and characterized $\mathrm{Cp}_{2} \mathrm{All}-\mathrm{L}$ derivatives of the following alcohols: exo- and endo-norboneols (-HONBL), bomeol (-HOBL), tenchol (H(JFI). 3-methyl-2norbornanemethanol (HOMNBNI) (each structure containing a bicyclo[2.2.1.]heptane moiety): 1- and 2adamantanols (HOAd). 2-methyl-2-adamantanol (HOMLd): menthol (HOMN). verbenol (HONBI) and 3-hydroxy-2-pinanone (HOPin). Naturally; several decomposition channels shown at the scheme are absent for certain individual compounds, while another pathways are present due to alcoso-ligand desiruction. According to the above scheme each molecular ion $\left[\mathrm{Cp}_{2} \mathrm{M}(\mathrm{OL})_{2}\right]^{*}$ could have three fragmentation possibilities realized by vleavages of $\mathrm{M}-\mathrm{Cp} . \mathrm{M}-()$ or $(-\mathrm{C})$ bonds resulting in losses of eyclopentadienyl. alcoholate ligand (OL) or oxygen free organic moiety (L) respectively. Each of the ions formed thereupon $\left[\mathrm{CpM}(\mathrm{OL})_{2}\right]^{+},[\mathrm{Cp} \mathrm{M}(\mathrm{OL})]^{-}$or $\left[\mathrm{Cp}_{2} \mathrm{M}(\mathrm{O})(\mathrm{OL} .)\right]^{+}$could in turn give nise to three further fragmentations which are conditioned by the same processes as it was observed for the molecular ion. Probabilities of each elementary process. when compared, enables us to evaluate $\mathrm{M}-\mathrm{O} . \mathrm{M}-\mathrm{C}$ and $\mathrm{M}-\mathrm{Cp}$ bonds strength and hence a trend to form oxide or carbide films in MOCVD processes.

A derivative of hafnocene and HOPin 2 reveals an extraordinary mass spectrometric behaviour. Both the molecular ion and its decomposition products have small intensities. [CpHFOC] ion is responsible for the main peak. It is interesting to note that it losses oxvgen rather readily that suggests a presence of direct $\mathrm{H} f-\mathrm{C}$ bond possibly via metallacycle tormation. 


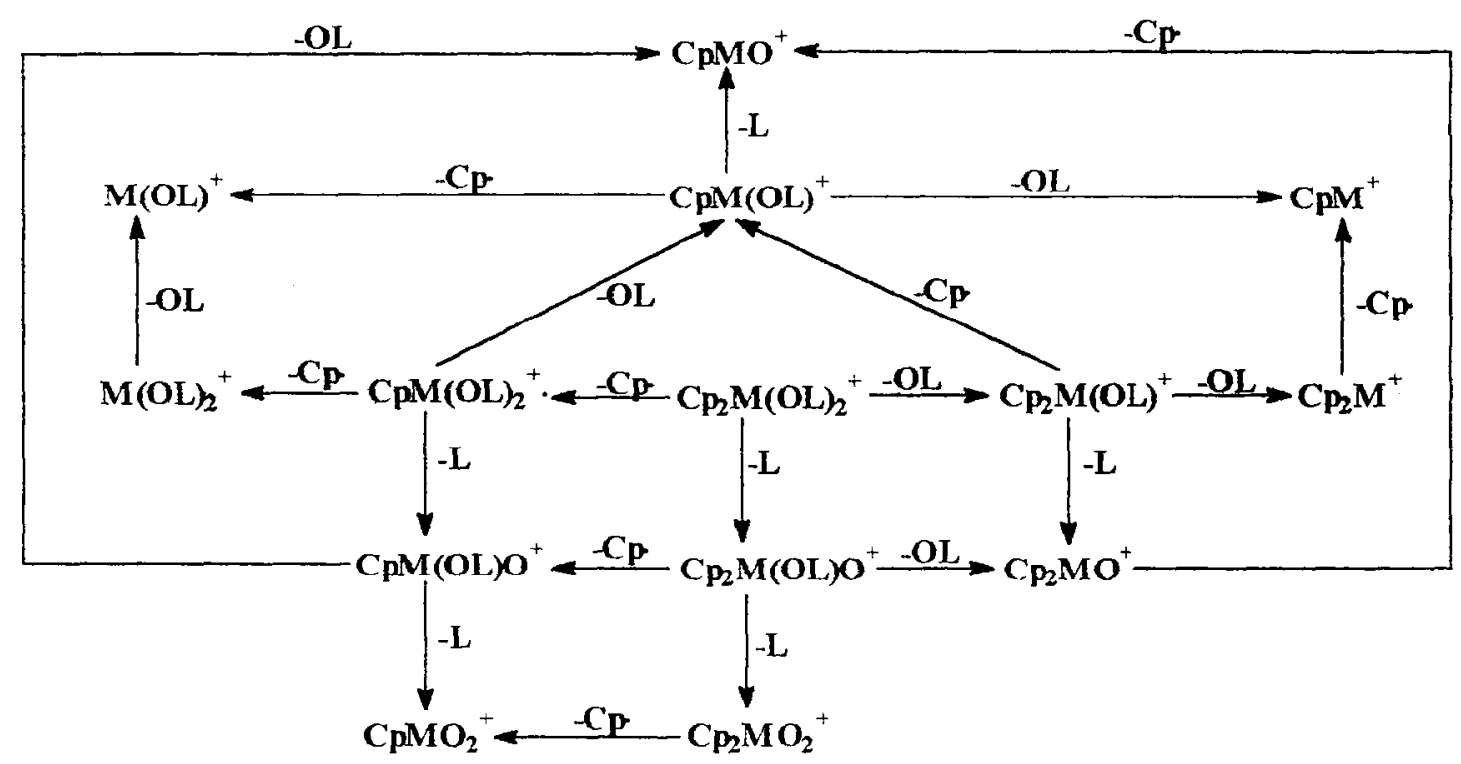

Fig.2. Generalized fragmentation pattern of $\mathrm{Cp}_{2} \mathrm{ML}$. complexes where $\mathrm{M}=\mathrm{Zr}, \mathrm{Hf} ; \mathrm{L}=\mathrm{OAlk}$.

(Possible appearance of ion-radical species vary strongly from one complex to another and therefore is not reflected)

Fragmentation patterns of zircono- and hafnocene complexes with mentholato-ligand ( 3 and 4 respectively) are characterized by a great number of possible channels due to menthol framework decomposition. Previously mass spectra were obtained and described only for free menthols [7]. The Cp. elimination is a dominant process for both compounds while the alternative -OMN one is nearly twice less intensive. When further decompositions are also considered, it is the M-O bond that appears to be the strongest. Evidently, these volatile precursors could be recommended chiefly for oxide films deposition.

The complexes $5\left[\mathrm{Cp}_{2} \mathrm{Zr}(\mathrm{OVBL})_{2}\right]$ and $6 \quad\left[\mathrm{Cp}_{2} \mathrm{Zr}(\mathrm{OVBL})_{2}\right]$ produce very many decomposition products as a result of a double bond presence within the ligand's framework and hence they could be preferably used for oxycarbide or graded films deposition.

Borneol, exo- and endo-norborneols has been previously investigated both as free alcohols [8] and. by us, as hafnocene derivatives [9]. In connection with this. we undertook a systematic study of zirconium analogues as well $7,8,8 \mathrm{a}$. As mass spectrometric data show the behaviour of corresponding organozirconium and organohafnium complexes is quite similar to each other. The above is also valid for HOFL derivatives of zirconocene 9 and hafnocene 10 which differ from 7 only by methyl substituents position. For this series of compounds some common features have been found out:

- the ligand elimination is the most probable process. If for $\mathbf{8}$ and $\mathbf{1 0}$ it is the $\mathrm{Cp}$ ligand, in all other cases the loss of the alcoxo-moiety plays a dominant role.

- cleavage of the C-O bond is not preferred at the first step, but becomes more evident at the further ones.

- bicyclo[2.2.1.]heptane moiety is stabilized by introduction of methyl substituents and could be eliminated as an entity.

The latter property is very useful for prevention of pyrocarbon formation in MOCV deposits.

A characteristic feature of two last representatives of bicyclo[2.2.1.] Theptane series is remoteness of the framework in -OMNBM ligand from $\mathrm{Zr}$ (IV) 11 or $\mathrm{Hf}(\mathrm{IV}) 12$ coordination centers. It was interesting to find out that in the molecular ions the $\mathrm{M}-\mathrm{O}$ bonds are the most liable ones, while $\mathrm{C}-\mathrm{C}$ bonds of the ligand are very strong which support the above idea of the stabilization of the bicyclic moiety when substituted by donor groups in lateral positions. Among possible pathways of the molecular ion fragmentation. elimination of $\mathrm{Cp}$ is prevalent in both cases. nevertheless this slight preterence in inverted of the further steps. The 
MNBM framework cleavage we remarked only for $\left[\mathrm{Cp}_{2} \mathrm{Hf}(\mathrm{O})(\mathrm{OMNBM})\right]^{+}$ion of 12 as $\mathrm{C}_{2} \mathrm{H}_{3} \mathrm{O}$ elimination whilst the remainder organic part was migrating to the central atom forming direct $\mathrm{Hf}-\mathrm{C}$ bond. These precursors seem to be very promising both as able to loose the whole ligand (as above) and because their destruction could be easily controlled by gas phase composition during the deposition process.

In order to find the limits of necessary and sufficient in shielding properties of the lateral ligands for conferring to the metallocene core enough volatility a series of bulky tricyclic adamantanoles has been synthesized and investigated. Nevertheless corresponding alcohols are very similar, the influence of the organic part onto $\mathrm{M}-\mathrm{O}$ bonds became immediately evident. E.g., zirconocene derivative of HOMAd 13 is unstable compound in the vapour phase because of steric tensions present in the structure: it's molecular ion could be found only as traces. At the same time the $\mathrm{M}-\mathrm{O}$ bond in it is the strongest one, hence consecutive cleavages of $\mathrm{C}-\mathrm{O}$ bonds with MAd framework elimination give rise to the main ion in the $\mathrm{EI}$ spectrum $\left[\mathrm{Cp}_{2} \mathrm{ZrO}_{2}\right]^{+}(\mathrm{m} / \mathrm{z}=252)$.

Bis-2-adamantanolate of hafnocene 14 is the compound having the weakest $\mathrm{M}-\mathrm{O}$ bond. It's main decomposition pathway consists of alcoxo-ligand loss followed by $\mathrm{C}_{2} \mathrm{H}_{3}$ discard leading to the principal peak $\left[\mathrm{Cp}_{2} \mathrm{Hf}\left(\mathrm{OC}_{8} \mathrm{H}_{12}\right)\right]^{+}(\mathrm{m} / \mathrm{z}=432)$. This fragmentation channel is finished by $\left[\mathrm{Cp}_{2} \mathrm{Hf}\right]^{+}(\mathrm{m} / \mathrm{z}=308)$. Mike spectra confirm no evidence of $\left[\mathrm{Cp}_{2} \mathrm{HfO}\right]^{+}$ion that is favourable for carbide deposits formation. Its zirconium analogue 15 is the most stable precursor among those containing Ad moiety: the molecular ion of it has the maximum intensity and both in EI and MIKE spectra its fragmentation occurs via $C p$ radical loss resulting in appearance of $\left[\mathrm{CpZr}(\mathrm{OAd}-2)_{2}\right]^{+}(\mathrm{m} / \mathrm{z}=457)$. Contrary to the 14 , the $\mathrm{Zr}-\mathrm{O}$ bond in 15 is quite strong, hence its further decomposition proceeds by consecutive $\mathrm{C}-\mathrm{O}$ bonds cleavages accompanied by adamantyl eliminations down to $\left[\mathrm{CpZrO}_{2}\right]^{+}(\mathrm{m} / \mathrm{z}=187)$.

Competitive losses of $\mathrm{Cp}$ or adamantoxy radical could be met at molecular ion fragmentation step of $\left[\mathrm{Cp}_{2} \mathrm{Hf}(\mathrm{OAd}-1)_{2}\right] 16$ and $\left[\mathrm{Cp}_{2} \mathrm{Hf}(\mathrm{OMAd})_{2}\right] 17$, but in both cases the main contribution to a total ionic current derives from the products of the former (i.e. - Cp) channel. For the complex 16 the fragment $\left[\mathrm{CpHf}(\mathrm{OAd}-1)_{2}\right]^{+}$is responsible for the principal peak in the MIKE spectrum $(\mathrm{m} / \mathrm{z}=545)$ this product generates very unstable $[\mathrm{CpHf}(\mathrm{O})(\mathrm{OAd}-1)]^{+}$ion at $\mathrm{m} / \mathrm{z}=410$ that in turn by $-\mathrm{OAd}-1$ or $-\mathrm{Ad}$ losses gives rise to $[\mathrm{CpHfO}]^{+}(\mathrm{m} / \mathrm{z}=275)$ and $[\mathrm{CpHfO}]^{+}(\mathrm{m} / \mathrm{z}=259)$ species. The methylated framework of 17 influence the precursor behaviour in a quite different way: after the first loss of $\mathrm{Cp}$ the ion $\left[\mathrm{CpHf}(\mathrm{OMAd})_{2}\right]^{+}$discards a methylene with formation of quite stable $[\mathrm{CpHf}(\mathrm{OMAd})(\mathrm{OAd}-2)]^{+}(\mathrm{m} / z=559)$ fragment that after further elimination of $\mathrm{Cp}$ gives rise to the main decomposition product $[\mathrm{Hf}(\mathrm{OMAd})(\mathrm{OAd}-2)]^{+}(\mathrm{m} / \mathrm{z}=494)$. Taking the above into a consideration we recommend these precursors for oxide films deposition.

Naturally, except the already discussed fragmentation processes for this series of compounds exist also processes of adamantane framework cleavage which sometimes badly complicate fragmentation patterns for particular precursors. One can observe an elimination of different hydrocarbon fragments or that of oxygene-containing species accompanied by the remaining moiety migration to the central atom with direct $\mathrm{M}-\mathrm{C}$ bonding. The simplest pattern was obtained for the compound 16 . It is interesting to note that process found by us often do not agree with fragmentation data obtained for free alcohols [10, 11], we explain these differences in mass spectrometric behaviour as a consequence of much more ionic M-O bond appearance instead of $\mathrm{H}-\mathrm{O}$ one.

Finally we would like to discuss briefly a compound of another type synthesized for curiosity i.e. bis-1-adamantylzirconocene. Naturally, its volatility is higher than that of alcoholate analogues but the most interesting was the fact non peculiar to the organometallic complexes in question - the molecular ion peak is the main one in the EI spectrum. The principal fragmentation pathway of this ion is of complex nature and, probably, consists of several steps. A product $\left[\mathrm{Cp}_{2} \mathrm{ZrC}_{9} \mathrm{H}_{12}\right]^{+}(\mathbf{m} / z=340)$ was formed which in turn gave rise to four daughter species: $\left[\mathrm{CpZrC}_{9} \mathrm{H}_{12}\right]^{+}(\mathrm{m} / \mathrm{z}=275) ;\left[\mathrm{Cp}_{2} \mathrm{ZrC}_{9-\mathrm{m}} \mathrm{H}_{12-n}\right]^{+}(\mathrm{m} / \mathrm{z}=325 ; 313 ; 297)$, where a hydrocarbon moiety $\mathrm{C}_{9} \mathrm{H}_{12}$ evidently has bicyclo[3.3.1.]nonane structure. The $\mathrm{M}$-Ad bond cleavage is among the less favoured processes. The above proves a suitability of this precursor for carbide films deposition.

\section{CONCLUSIONS}

Bearing in mind what processes are prevalent at the step of molecular ion fragmentation from one hand, and what kind of products are responsible for the major part of the total ionic current from the 
another, we assume it possible to make some preliminary conclusions about dominant tendencies taking place for the precursors in question decomposition in absence of any outside influences. From the above points of view the compounds $3,4,10,13,15,16,17$ could be recommended for oxide deposits formation. A pronounced trend to carbides deposition reveal alcoholato-derivatives 7 and 14 and, naturally, bis-1-adamantylzirconocene. It should not be forgotten that in real MOCVD process prerequisites mentioned have to find further support and development in so called outside influences, i.e. gas phase composition, application of high frequency electromagnetic fields, UV-irradiation etc. It is also valid for a remaining group of precursors which have no preferences in their fragmentation patterns demonstrating a borderline equilibrium that could be easily shifted and controlled by the above factors. As an illustrative example of the precursor structure intluence we would like to remember here the compound 2 where the center of coordination in surrounded by four oxygen atoms, but it is the hydrocarbon periphery of acyloine ligand that predetermines the precursors decomposition leading to oxycarbide species.

Organoindium compounds discussed in the section 2.1. could be recommended for semiconducting materials synthesis both as those having a pronounced tendency to free metal ion formation and more stable precursors with respect to known alkylindium species.

\section{Acknowledgements}

Some of us (A.V.G. and I.A.G.) are grateful to ICTIMA-CNR (Padua, Italy) for financial support of their research and stay in Italy.

\section{References}

[1] Razurvayev G.A. Application of organometallic compounds for obtaining of inorganic materials and coatings (Nauka, Moscow, 1986) pp. 3-4; 84-93.

[2] Mazurenko E.A. Synthesis, structure and stability of metal $\beta$-diketonates in a gas phase and gas phase reactions on their basis, Dr.Sci.(Chem.) Thesis (IGIC Acad.Sci.UkrSSR, Kiev, 1987, 300 p.

[3] Whiteley J.S., Chanclhi S.K., J.Electrochem.Soc., 129 (1982) pp.383-388.

[4] Zanella P., Rossetto G., Brianese N., Ossola F., Porchia M., Chem. Mater., 3 (1991), pp. 225 - 241.

[5] Razuvayev G.A. Deposition of films and coatings by organometallic compounds decomposition (Nauka, Moscow, 1981) 322 p.

[6] Stor A., Thomas B.S., J.Chem.Soc.(A), (1971) pp. 3850 - 3854.

[7] Thomas A.F., Willhalm B., J.Chem.Soc.. (1966) pp. 219 - 227.

[8] Holmes J.L., Mc Gilivray D., Org.Mass Spectrom., 7 (1973), pp. 559 - 572.

[9] Grafov A.V., Favretto D., Traldi P., Battiston G.A., Porchia M., Rossetto G., Zanella P., Rapid Commun. Mass Spectrom., 7 (1993), pp.158-162.

[10] Chizhov O.S., Novikov S.S., Yurchenko A.G., Danilenko G.I. Izvestija AN SSSR (ser. Khim.), (1972), pp.337 - 342.

[11] Doleysek Z., Hala S., Hanus V., Landa S., Coll.Czec.Chem.Commun., 31 (1966), pp. 435 - 449 